\title{
Foaming of industrial lean methyldiethanolamine solution in the presence of hydrocarbon and fatty acid based corrosion inhibitors
}

\author{
Mohammad Keewan, Fawzi Banat, Priyabrata Pal*, Jerina Zain, and Emad Alhseinat \\ Department of Chemical Engineering, Khalifa University, Abu Dhabi, P.O. Box 2533, United Arab Emirates
}

Received: 19 June 2018 / Accepted: 2 October 2018

\begin{abstract}
In natural gas sweetening alkanolamine processes one of the regularly used chemical is the corrosion inhibitor. For better operation of the plant it is essential to understand the effect of their presence on foaming of industrial lean Methyldiethanolamine (MDEA) used as solvents at different temperatures. This study aimed at investigating the effect of HydroCarbon Based (HCB) and fatty acid based corrosion inhibitor having chemical name Bis(2-Hydroxyethyl)Cocoalkylamine (BHCL) on the foaming tendency of industrial real lean MDEA solutions. Experiments were conducted with different operating parameters, including liquid volume of the solution, foaming time, flow rate of nitrogen gas, concentration of the corrosion inhibitors, temperature of the solution, and gas diffuser pore size using the Foam Scan instrument. With the increase in solution volume and foaming time foaming happens to be more. The foaming tendency of lean MDEA solutions decreased with increasing temperature in absence of corrosion inhibitors but showed different behavior in their presence. At small diffuser pore size and high gas flow rate, the final foam volume increased in the presence of $\mathrm{HCB}$ but decreased with the BHCL inhibitor. Optimizing the operating parameters to minimize foaming was verified to be a function of the type of inhibitor used.
\end{abstract}

\section{Introduction}

Natural gas with hydrogen sulfide $\left(\mathrm{H}_{2} \mathrm{~S}\right)$ levels exceeding $5.7 \mathrm{mg} / \mathrm{m}^{3}$ of the total, along with carbon dioxide $\left(\mathrm{CO}_{2}\right)$ and other compounds such as carbon disulfide $\left(\mathrm{CS}_{2}\right)$, carbonyl sulfide (COS), and mercaptans (R-SH), is collectively termed as sour gas (Arnold and Stewart, 1995). Highly acidic compounds like $\mathrm{H}_{2} \mathrm{~S}$ and $\mathrm{CO}_{2}$, can be extremely harmful, corrosive and lethal to breath. Henceforth, eradicating these from sour gas is a vital step and the process is called natural gas sweetening (Mokhatab and Poe, 2012). Absorption process based on tertiary alkanolamine (methyldiethanolamine, MDEA), is one of the widely used methods for desulphurization of natural gas. However, over a longer period of continuous operation, the foaming of lean MDEA caused by several pollutants is significant, which leads to numerous problems, such as absorbent loss, pipeline corrosion, decreased hydrocarbon yield, reduction in mass transfer area and efficiency and carryover of alkanolamine solution to the downstream, thereby fluctuating operation parameters and ultimately increasing the cost of operation (Alhseinat et al., 2014; Chen et al., 2011). Mechanically injecting a gas into a liquid produces bubbles and the gas bubbles rises at the top of the liquid level to

\footnotetext{
* Corresponding author: pal.priyabrata@ku.ac.ae
}

create foams containing closely packed liquid matrix (Drenckhan and Saint-Jalmes, 2015). The foaming tendency and the foam stability are the two main parameters to be expressed as the foaming problem. The foam volume is measured as the height above the liquid solution and the foam stability is measured as a function of time resistance to break the last bubble of the foam into a continuous liquid phase (Alhseinat et al., 2014; Pilon et al., 2002).

Corrosion in alkanolamine based acid gas capture process is another major operational problems which affect safety as well as process economics. Two types of corrosion such as localized corrosion and uniform corrosion can be found within the process. Several methods such as process and equipment design, use of different corrosion-resistant materials, and corrosion inhibitors are commonly used to be applied to mitigate corrosion. The use of corrosion inhibitor is one of the most acceptable method as it can be applied without any process modification (Dupart et al., 1993; Srinivasan et al., 2013). Among different types of corrosion inhibitors, organic compounds are one of the most effective means of controlling the common form of internal corrosion present in oil and gas industries (Olajire, 2017). The compound provides a protective hydrophobic film on the metal surfaces which prevents the dissolution of the metal ions in the solution (Yaro et al., 2013). Generally, two types of corrosion inhibitors are used in the gas sweetening industries. Among them, HydroCarbon Based (HCB) 
corrosion inhibitors are widely used due to the formation of emulsion and wettability on the surface (Papavinasam et al., 2007). While, fatty acid based corrosion inhibitors having chemical name (Bis(2-Hydroxyethyl)Cocoalkylamine; BHCL) contains oxygen and nitrogen atoms which is adsorbed on the metal surface to block the active corrosion sites (El-Haddad, 2013). It has also presumed that corrosion inhibitors play main role in the foaming tendency of the alkanolamine gas sweetening unit (Alhseinat et al., 2015a). Foaming is mainly caused by contaminants that include corrosion inhibitors regularly used for pipelines, amine degradation products, suspended solids like iron (II) sulfide which increases the stability of the foam, contaminant chemicals from boiler feed water treatment, foreign matters, and antifoam agents if used in excess (Abry and Dupart, 1995; Al Dhafeeri, 2007; Alhseinat et al., 2015a,b; Kohl and Nielsen, 1997). Recently, foaming has been tested using fresh MDEA solutions, using $\mathrm{HCB}$ and fatty acid based corrosion inhibitors (BHCL) (Keewan et al., 2018a). Indeed, the effect of foaming on industrial real lean MDEA solutions by the addition of the corrosion inhibitors has not yet been reported.

The main aim of this work is to see the effect of several operating parameters on the foaming behavior of industrial real lean MDEA solutions in the presence of two types of corrosion inhibitors, namely, hydrocarbon-based and fatty-acid based inhibitors, and to compare with the foaming tendency of lean MDEA in the presence of these inhibitors. The physical properties such as density, dynamic viscosity, and surface tension of all the solutions were experimentally determined. A Foam Scan instrument with nitrogen gas was used for the foaming tests. The effect of several operating parameters, such as liquid volume, time of foaming, solution temperature, the gas diffuser pore size, and type of corrosion inhibitor and their concentration, were investigated.

\section{Materials and methods}

\subsection{Materials}

The industrial real lean MDEA solutions were obtained from ADNOC Gas Processing Company (Habshan, Abu Dhabi). The HCB corrosion inhibitor was purchased from the company Baker Hughes, USA while the BHCL was obtained from the Swedish Company AkzoNobel (AkzoNobel, 2008).

\subsection{Instruments used}

The density and dynamic viscosity of all the solutions were measured using Lovis $2000 \mathrm{M} / \mathrm{ME}$ micro viscometer (Anton Paar, USA) with an error of $0.5 \%$ in dynamic viscosity. The instrument DCTA 21, Dataphysics (Germany) was used to measure the surface tension of all the solutions. A Wilhelmy platinum-iridium plate (PT 11) was used for the surface tension analysis with an error of $\pm 0.030 \mathrm{mN} / \mathrm{m}$. The Foam Scan instrument (TECLIS, France) was used to carry out all the foaming experiments.

\subsection{Foaming experiments}

A fixed amount of the lean MDEA solution was incorporated inside the cuvette of the Foam Scan instrument by the sampling pipe without mechanical stirring. At the bottom of the cuvette nitrogen gas was introduced at a particular flow rate using a glass frit having specific pore size. For a specific period of time the nitrogen gas was passed to produce bubbles in the lean MDEA solutions. The foam volume generated at the top of the liquid level was recorded after the nitrogen flow was stopped.

\section{Results and discussion}

\subsection{Characterization of industrial real lean MDEA solutions}

The physical properties of industrial real lean MDEA solutions are important to understand the foaming behavior. The aqueous light yellow lean MDEA (45.0 wt.\%) solution having $\mathrm{pH} 10.54$ was collected leaving the regenerator of the operating plant. The density, dynamic viscosity, and surface tension of industrial lean MDEA solutions alone and in presence of corrosion inhibitors at different concentrations and temperatures were experimentally determined and are shown in Table 1. Similar results from different batch of lean MDEA were also reported in our previous work (Keewan et al., 2018b). The lean MDEA was found to have total organic acid anions of $3405 \mathrm{mg} / \mathrm{L}$ including organic degraded products such as diethanolamine (1.4\%), triethanolamine (0.5 wt.\%), bicine (0.3 wt.), etc. Also, inorganic ions such as sulfide, sulfate, thiosulfate, phosphate, chloride up to $100 \mathrm{mg} / \mathrm{L}$ and traces of metal ions like iron, chromium, lead, magnesium, aluminium, zinc, etc. were detected in the lean MDEA solution (Pal and Banat, 2016).

\subsection{Foaming experiments}

For all the foaming experiments with corrosion inhibitors at different operating conditions, the foaming of lean MDEA solution was considered to be the base line. All the experiments were repeated thrice to obtain the standard deviations below $5 \%$.

\subsubsection{Liquid level with lean MDEA}

Figure 1 shows the effect of initial lean MDEA volume at four different nitrogen flow rates. It was observed that at $30 \mathrm{~mL}$ of the liquid level no foaming was observed. There may be two possible explanations for such an observation. Firstly, this could be due to very short period of interaction between the gas and the liquid phase or secondly, due to insufficient hydrostatic force impacting the buoyancy force for bubble production (Thitakamol et al., 2009). Although, foaming was observed increasing the initial liquid volume to $45 \mathrm{~mL}$ at $400 \mathrm{~mL} / \mathrm{min}$ nitrogen flow rate, no foam was seen at lower $(100-300 \mathrm{~mL} / \mathrm{min})$ flow rates. Foaming was also observed at liquid volume of $45 \mathrm{~mL}$ using $50 \mathrm{wt} . \%$ fresh MDEA (Keewan et al., 2018a). After increasing the initial liquid volume to $60 \mathrm{~mL}$, the foam volume increased 
Table 1. Physical properties of lean MDEA solutions in presence of corrosion inhibitors.

\begin{tabular}{lccc}
\hline Samples & $\begin{array}{c}\text { Density }(\rho) \\
\mathrm{kg} / \mathrm{m}^{3}\end{array}$ & $\begin{array}{c}\text { Dynamic viscosity } \\
(\mu) \mathrm{mPa} \mathrm{s}\end{array}$ & $\begin{array}{c}\text { Surface tension } \\
(\gamma L) \mathrm{mN} / \mathrm{m}\end{array}$ \\
\hline Lean MDEA @ $20{ }^{\circ} \mathrm{C}$ & 1044.31 & 7.15 & 46.67 \\
Lean MDEA @ $65{ }^{\circ} \mathrm{C}$ & 1015.91 & 6.93 & 43.26 \\
Lean MDEA with 0.05 wt.\% HCB @ $20{ }^{\circ} \mathrm{C}$ & 1043.52 & 6.83 & 42.83 \\
Lean MDEA with 0.1 wt.\% HCB @ $20{ }^{\circ} \mathrm{C}$ & 1043.76 & 6.84 & 45.66 \\
Lean MDEA with 0.05 wt.\% HCB @ $65{ }^{\circ} \mathrm{C}$ & 1014.96 & 6.89 & 40.23 \\
Lean MDEA with 0.05 wt.\% BHCL @ $20{ }^{\circ} \mathrm{C}$ & 1043.60 & 6.86 & 27.47 \\
Lean MDEA with 0.1 wt.\% BHCL @ $20{ }^{\circ} \mathrm{C}$ & 1043.76 & 7.35 & 28.04 \\
Lean MDEA with 0.05 wt.\% BHCL @ $65{ }^{\circ} \mathrm{C}$ & 1015.98 & 6.90 & 27.12 \\
\hline
\end{tabular}

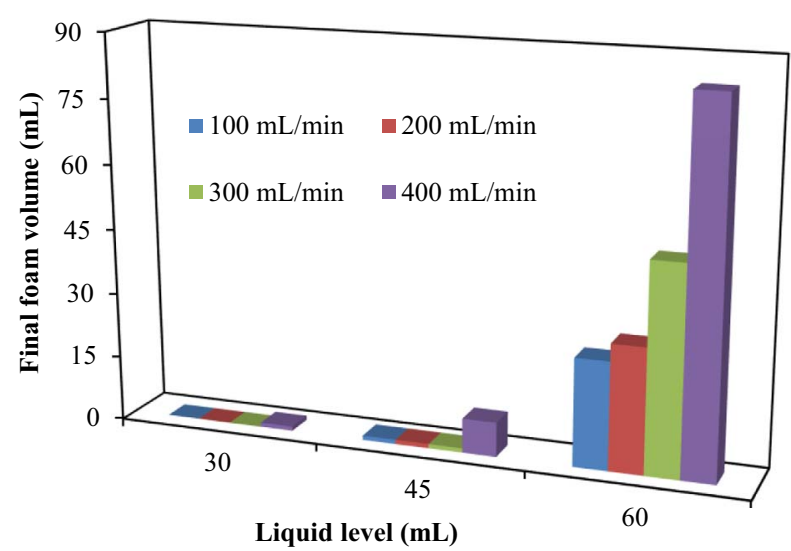

Fig. 1. Effect of final foam volume on liquid level of lean MDEA using different nitrogen flow rates having time of foaming $120 \mathrm{~s}$ at temperature $20^{\circ} \mathrm{C}$ using P3 glass frit.

significantly with increasing nitrogen flow rates from 100 to $400 \mathrm{~mL} / \mathrm{min}$. Since these experimental findings were also in good accordance with earlier reported work by other researchers (Thitakamol and Veawab, 2009), all the succeeding experiments would be carried out at $60 \mathrm{~mL}$ of the liquid level.

\subsection{Time of foaming}

\subsubsection{For lean MDEA}

Figure 2 shows the final foam volume at three different foaming times $(60,90$, and $120 \mathrm{~s})$ and four different nitrogen flow rates on lean MDEA liquid level of $60 \mathrm{~mL}$. The final foam volume of lean MDEA solution was found to be increased with the increase in the time of foaming at all the nitrogen flow rates. The foaming tendency of lean MDEA solutions was enhanced with the increase in the nitrogen flow rate and foaming time. At $120 \mathrm{~s}$, the foam volume from $25 \mathrm{~mL}$ at $100 \mathrm{~mL} / \mathrm{min}$ increased to $84 \mathrm{~mL}$ at $400 \mathrm{~mL} / \mathrm{min}$. At higher nitrogen flow rates the more number of bubbles are created in contact with liquid phases to obtain more foam volume (Kulkarni and Joshi, 2005).

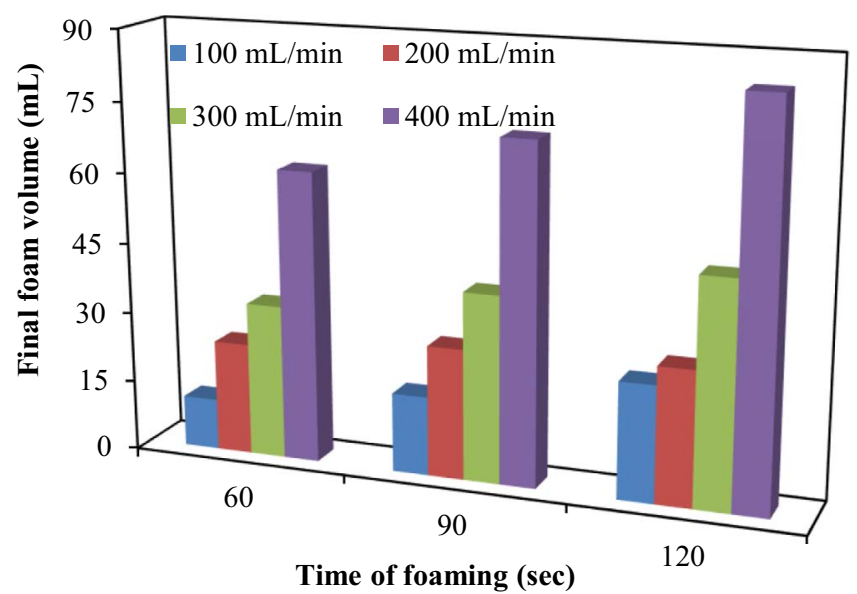

Fig. 2. The final foam volume with time of foaming for lean MDEA solutions at the liquid level of $60 \mathrm{~mL}$ and temperature $20{ }^{\circ} \mathrm{C}$ using P3 glass frit.

\subsubsection{In presence of $\mathrm{HCB}$}

At two different concentrations of $\mathrm{HCB}(0.05$ and $0.1 \mathrm{wt} . \%$ $\mathrm{HCB}$ ), the foaming trend was similar as observed for the lean MDEA (Fig. 3). However, the final foam volume was much lower than that was found in lean MDEA. Final foam volume of $19 \mathrm{~mL}$ was obtained using $120 \mathrm{~s}$ of foaming time at nitrogen flow rate of $400 \mathrm{~mL} / \mathrm{min}$ and reduced to $11 \mathrm{~mL}$ at $100 \mathrm{~mL} / \mathrm{min}$ for $0.05 \mathrm{wt} . \%$ HCB (Fig. 3a). The trend was more pronounced at higher concentrations $(0.1 \mathrm{wt} . \%)$ of $\mathrm{HCB}$ on lean MDEA at $20^{\circ} \mathrm{C}$ (Fig. 3b), while, 0.1 wt. $\%$ HCB in presence of fresh MDEA (50 wt.\%) solution showed foaming only at higher nitrogen flow rates (Keewan et al., 2018a). The surface tension of the industrial real lean MDEA solution in the presence of 0.05 wt.\% HCB corrosion inhibitor was found to be $42.83 \mathrm{mN} / \mathrm{m}$ and decreased to $40.23 \mathrm{mN} / \mathrm{m}$ at $0.1 \mathrm{wt} . \% \mathrm{HCB}$, respectively (Alhseinat et al., 2015a).

\subsubsection{In presence of $B H C L$}

The foam volumes for 0.05 and 0.1 wt.\% BHCL corrosion inhibitors on lean MDEA were found to be more than that 


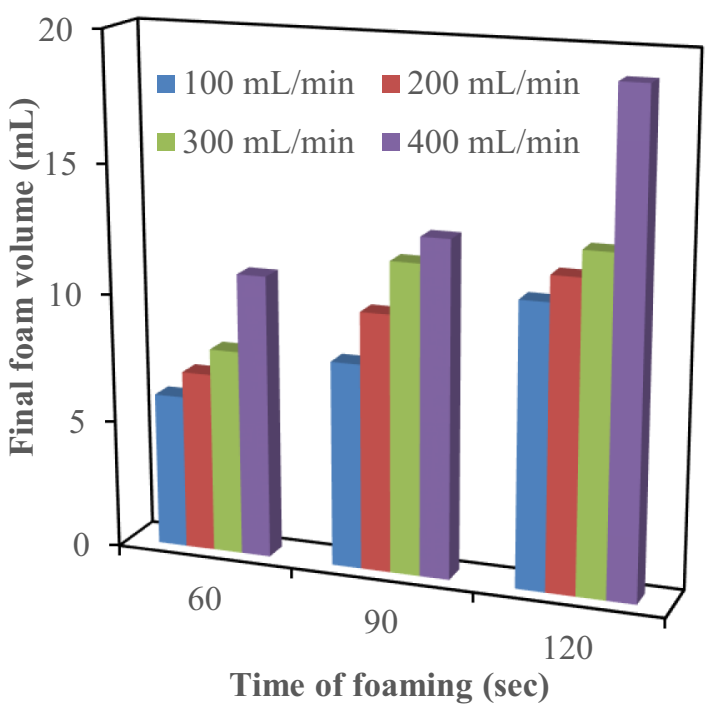

(a)

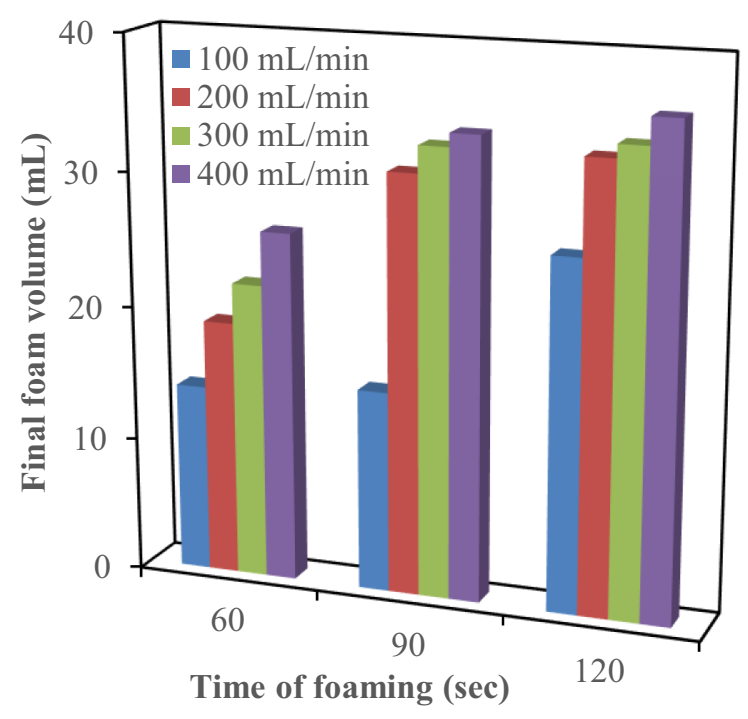

(b)

Fig. 3. The final foam volume with different time of foaming for HCB concentration (a) 0.05 wt. $\%$ and (b) 0.1 wt.\% at the liquid level of $60 \mathrm{~mL}$ and temperature $20^{\circ} \mathrm{C}$ using $\mathrm{P} 3$ glass frit.

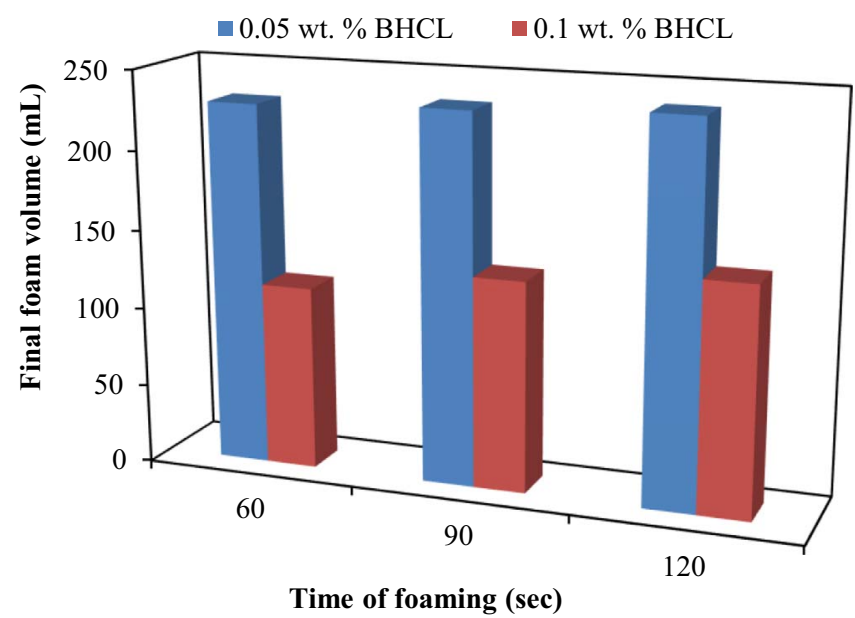

Fig. 4. The final foam volume with BHCL corrosion inhibitor at the liquid level of $60 \mathrm{~mL}$ and temperature $20^{\circ} \mathrm{C}$ having nitrogen flow rate $400 \mathrm{~mL} / \mathrm{min}$ using $\mathrm{P} 2$ glass frit.

obtained only for lean MDEA. The increment of foam volume was very less with increasing foaming time at both the concentrations (Fig. 4). A similar trend was obtained containing $50 \mathrm{wt} . \%$ fresh MDEA in the presence of BHCL at nitrogen flow rates of 300 and $400 \mathrm{~mL} / \mathrm{min}$ (Keewan et al., 2018a). At BHCL concentration of 0.05 wt.\%, the foam volume was high $(238 \mathrm{~mL})$ compare to low foam volume $(144 \mathrm{~mL})$ at BHCL concentration of $0.1 \mathrm{wt} . \%$, having $400 \mathrm{~mL} / \mathrm{min}$ gas flow rate and at foaming time of $120 \mathrm{~s}$. The increase in concentration of the BHCL from 0.05 wt.\% to 0.1 wt.\% in lean MDEA solution increases

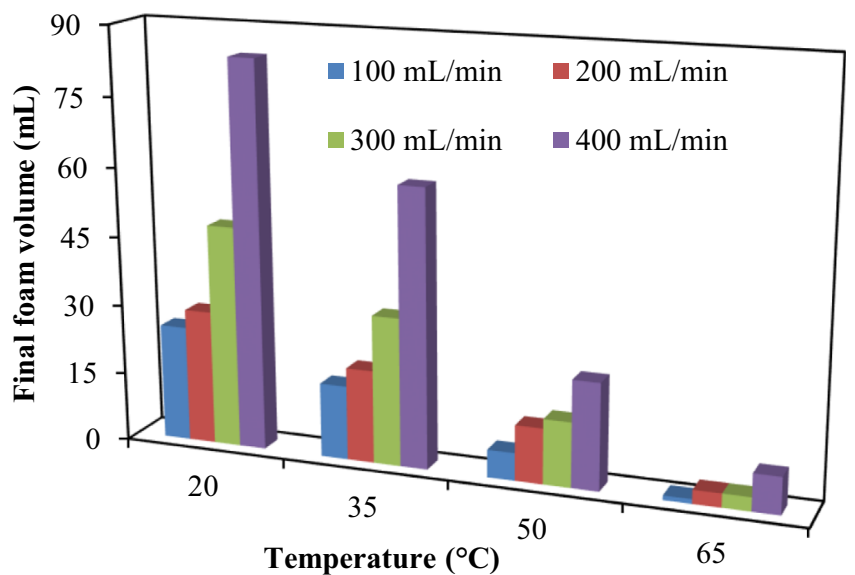

Fig. 5. The final foam volume with the increase in lean MDEA solution temperature for different nitrogen flow rates at the liquid level of $60 \mathrm{~mL}$ and at foaming time of $120 \mathrm{~s}$ using P3 glass frit.

the surface tension of the solution from $27.47 \mathrm{mN} / \mathrm{m}$ to $28.04 \mathrm{mN} / \mathrm{m}$, respectively. According to El-Haddad (2013), since BHCL is a fatty acid based corrosion inhibitor, it can easily be adsorbed on to the surface of the bubbles to obtain the desired result.

\subsection{Temperature of the solution}

\subsubsection{For lean MDEA}

Figure 5 shows the final foam volume with the increase in lean MDEA solution temperature. The final foam volume 


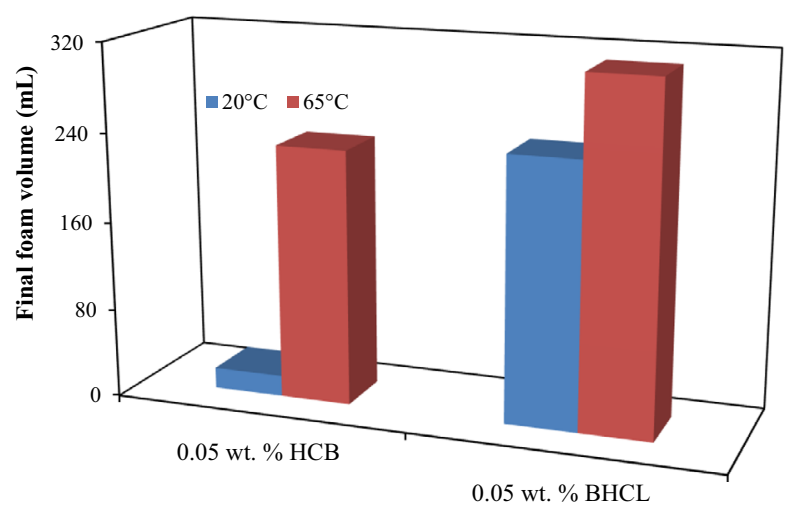

Types of corrosion inhibitor on lean MDEA

Fig. 6. The final foam volume with temperature in presence of corrosion inhibitors at the liquid level of $60 \mathrm{~mL}$ and at foaming time of $120 \mathrm{~s}$ having nitrogen flow rate $400 \mathrm{~mL} / \mathrm{min}$.

decreased significantly as the temperature increased from $20{ }^{\circ} \mathrm{C}$ to $65^{\circ} \mathrm{C}$. At $400 \mathrm{~mL} / \mathrm{min}$ nitrogen flow rate, the final foam volume of $84 \mathrm{~mL}$ reduced to $8 \mathrm{~mL}$ as the temperature increased from $20{ }^{\circ} \mathrm{C}$ to $65^{\circ} \mathrm{C}$. The increase in temperature of the solution reduces the dynamic viscosity of lean MDEA solution from $7.15 \mathrm{mPa}$ s to $6.93 \mathrm{mPa}$ s to obtain a lower foam volume (Thitakamol and Veawab, 2008).

\subsubsection{In presence of $H C B$ or $B H C L$}

The foam volume profile for both HCB and BHCL corrosion inhibitors, having concentrations of $0.05 \mathrm{wt} . \%$ at two different temperatures, is shown in Figure 6. At $20{ }^{\circ} \mathrm{C}$, the foaming tendency of lean MDEA was higher compared to $\mathrm{HCB}$ and less with respect to BHCL. While, at the higher temperature $\left(65^{\circ} \mathrm{C}\right)$, lean MDEA showed negligible foaming, compared to high foaming tendencies in presence of both the corrosion inhibitors. This behavior could be attributed to the fact that at a higher temperature in presence of corrosion inhibitors, the solution surface tension decreased while the dynamic viscosity remain almost constant to obtain higher foam volume (Aguila-Hernandez et al., 2007; Thitakamol and Veawab, 2009). A similar trend was observed using a P3 glass frit for HCB or BHCL corrosion inhibitors, having concentrations of 0.05 wt.\% present in fresh MDEA (Keewan et al., 2018a).

\subsection{Use of different pore size glass frit}

\subsubsection{For lean MDEA}

To investigate the effect of the glass frit (gas diffuser) on lean methyldiethanolamine foaming, different glass frits with varying pore sizes were used: P4 (10-16) $\mu \mathrm{m}, \mathrm{P} 3(16-40) \mu \mathrm{m}$ and P2 (40-100) $\mu \mathrm{m}$. Figure 7 shows the final foam volume of lean MDEA solution for all glass frits. With the smallest pore size (P4), no foam was observed, resulting in zero foam volume. The final volume of the foam increased significantly when the glass frit having intermediate pore size of P3 (16-40) $\mu \mathrm{m}$ was used. However, the final foam volume decreased when the glass frit having maximum pore size of

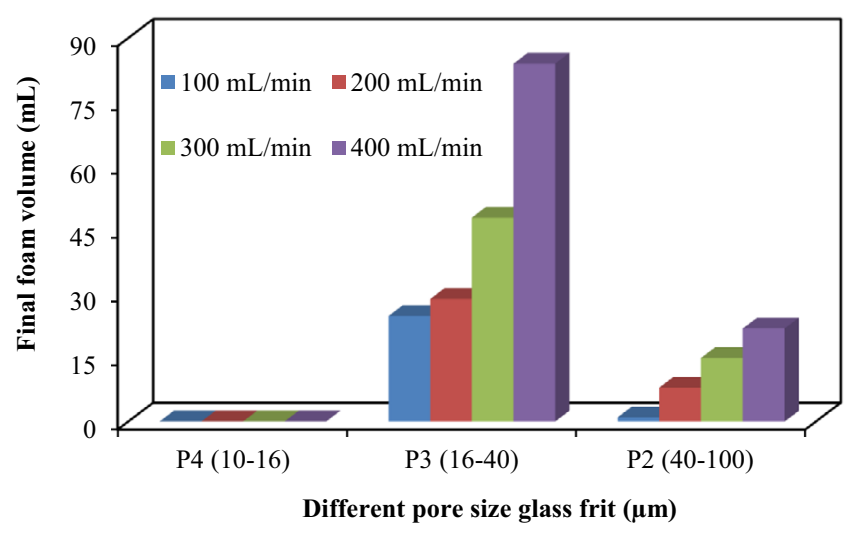

Fig. 7. The final foam volume of lean MDEA solution by using different pore size glass frit at foaming time $120 \mathrm{~s}$ and temperature $20{ }^{\circ} \mathrm{C}$.

P2 (40-100) $\mu \mathrm{m}$ was used. The mechanism involved of foam formation can be well explained from previous studies (Tse et al., 2003). For the smallest pore size, the bubbles produced are too small to overcome the hydrostatic and surface forces, and thus it was not possible to be detached from the diffuser. However, to overcome both the hydrostatic and surface forces the glass frit having pore size P3 is just sufficient to produce bubbles which create a buoyancy force to obtain the foam. Again, using the largest pore size glass frit P2, the foam volume further decreased, showing larger bubble production. Thus, the buoyancy force of the bubble was less to overcome the hydrostatic force (Tse et al., 1998).

\subsubsection{In presence of $H C B$}

Similarly, the effect of three different glass frits on the foaming tendency for 0.05 wt.\% HCB corrosion inhibitor at $20{ }^{\circ} \mathrm{C}$ was studied (Fig. 8). Pore sizes showed a parabolic path rather than a linear relationship with the final foam volume, and found a similar trend, as seen in the case of lean MDEA solution. At the smallest pore size P4 of $(16-40) \mu \mathrm{m}$, no foam was observed. Maximum foam volume was observed when the P3 glass frit pore size of (16-40) $\mu \mathrm{m}$ was used. However, using the P2 (40-100) $\mu \mathrm{m}$ glass frit, a reduction in foam volume was obtained. The foam volume was found to be much more pronounced for 50 wt.\% fresh MDEA than for industrial real MDEA solutions. For 50 wt.\% fresh MDEA containing 0.05 wt.\% HCB at $50{ }^{\circ} \mathrm{C}$ and with a foaming time of $60 \mathrm{~s}$ using the P3 glass frit, the final foam volume of $78 \mathrm{~mL}$ was reduced to $55 \mathrm{~mL}$ using the P2 glass frit (Keewan et al., 2018a).

\subsubsection{In presence of $B H C L$}

The final foam volume containing BHCL concentration 0.05 wt.\% in lean MDEA solution by using different glass frit pore size at foaming time $120 \mathrm{~s}$ and temperature $20^{\circ} \mathrm{C}$ is shown in Figure 9. Using the glass frit having intermediate pore size of P3 $(16-40) \mu \mathrm{m}$, the increment in the final foam volume was found to be from $7 \mathrm{~mL}$ to $37 \mathrm{~mL}$, increasing the flow rate of nitrogen from $100 \mathrm{~mL} /$ 


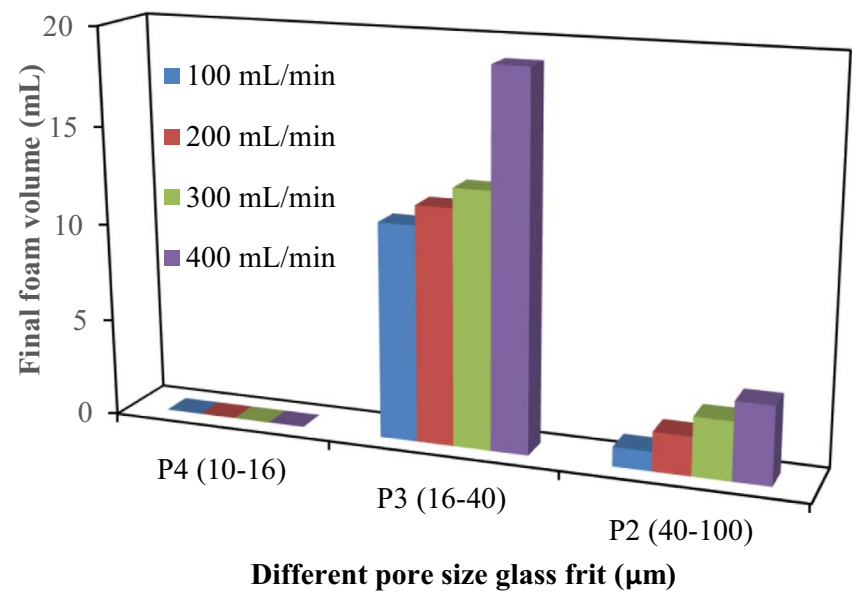

Fig. 8. The final foam volume for $\mathrm{HCB}$ concentration 0.05 wt.\% in lean MDEA by using different pore size glass frit at foaming time $120 \mathrm{~s}$ and temperature $20^{\circ} \mathrm{C}$.

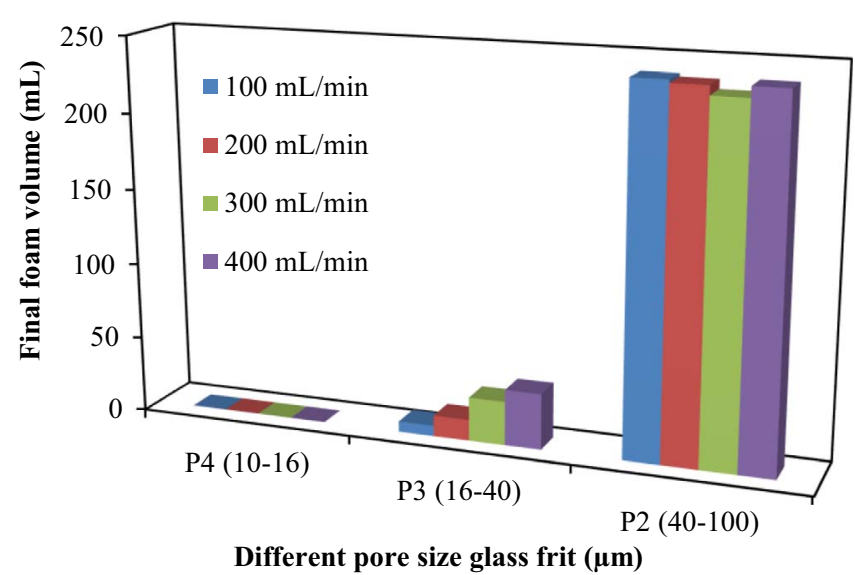

Fig. 9. The final foam volume for BHCL concentration 0.05 wt.\% in lean MDEA by using different pore size glass frit at foaming time $120 \mathrm{~s}$ and temperature $20^{\circ} \mathrm{C}$.

min to $400 \mathrm{~mL} / \mathrm{min}$. The highest foam volume was observed using the glass frit having largest pore size of P2 (40-100) $\mu \mathrm{m}$. A similar trend of final foam volume was observed in the presence of BHCL (0.05 wt.\%) present in fresh MDEA (50 wt.\%) solutions (Keewan et al., 2018a).

\section{Conclusion}

The foaming and the foam bubble characteristics of industrial lean MDEA in presence of hydrocarbon based and fatty acid based corrosion inhibitors at different operating parameters were investigated. This research work showed that the foaming tendency increased with the increase in foaming time. Interestingly, as the nitrogen flow rate increased the final foam volume in the presence of the HCB also increased but decreased in the presence of BHCL corrosion inhibitor. The foam volume of lean MDEA solution decreased with the increase in solution temperature; however, in the presence of corrosion inhibitors the final foam volume increased. Increasing the gas bubble size by using the glass frit having largest pore size reduced the foam volume in the presence of the HCB inhibitor but increased it in the presence of the fatty acid based (BHCL) corrosion inhibitor. Thus, appropriate choice of corrosion inhibitors and their operating parameters play a major role in minimizing the foaming tendencies in industrial real lean MDEA solutions.

Acknowledgments. The authors are grateful to the Gas Processing and Materials Science Research Center (GRC), Khalifa University, Abu Dhabi for funding the project under grant number GRC006. Sincere thanks to the ADNOC Gas Processing Company for their co-operation and support. We would like to thank Dr. Mark Wyatt, for checking the English language of the manuscript and Mr. Ismaila Shittu, for the estimation of physical properties of the solutions.

\section{References}

Abry R.G.F., Dupart R.S. (1995) Amine plant troubleshooting and optimization, Hydro. Proc. 4, 41-50.

Aguila-Hernandez J., Trejo A., Garcia-Flores B.E. (2007) Surface tension and foam behaviour of aqueous solutions of blends of three alkanolamines, as a function of temperature, Coll. Surf. A: Phy. Eng. Asp. 308, 33-46.

AkzoNobel (May 2008) AkzoNobel surface chemistry in the oil industry, https://www.akzonobel.com

Al Dhafeeri M.A. (2007) Identifying sources key to detailed troubleshooting of amine foaming, Oil Gas J. 105, 1-12.

Alhseinat E., Amr M., Jumah R., Banat F. (2015a) Removal of MDEA foam creators using foam fractionation: Parametric study coupled with foam characterization, J. Nat. Gas Sci. Eng. 26, 502-509.

Alhseinat E., Pal P., Ganesan A., Banat F. (2015b) Effect of MDEA degradation products on foaming behavior and physical properties of aqueous MDEA solutions, Int. J. Green. Gas Con. 37, 280-286.

Alhseinat E., Pal P., Keewan M., Banat F. (2014) Foaming study combined with physical characterization of aqueous MDEA gas sweetening solutions, J. Nat. Gas Sci. Eng. 17, 49-57.

Arnold K., Stewart M. (1995) Surface production operations: Design of gas-handling systems and facilities, Gulf Publishing Co, Houston, USA.

Chen X., Freeman S.A., Rochelle G. (2011) Foaming of aqueous piperazine and monoethanolamine for $\mathrm{CO}_{2}$ capture, Int. J. Green. Gas Con. 5, 381-386.

Drenckhan W., Saint-Jalmes A. (2015) The science of foaming, Adv. Coll. Inter. Sci. 222, 228-259.

Dupart M.S., Bacon T.R., Edwards D.J. (1993) Understanding corrosion in alkanolamine gas treating plants, Hydro. Proc. 93, $75-80$.

El-Haddad M.N. (2013) Chitosan as a green inhibitor for copper corrosion in acidic medium, Inter. J. Bio. Macro. 55, 142-149.

Keewan M., Banat F., Alhseinat E., Zain J., Pal P. (2018a) Effect of operating parameters and corrosion inhibitors on foaming behavior of aqueous methyldiethanolamine solutions, J. Pet. Sci. Eng. 165, 358-364. 
Keewan M., Banat F., Alhseinat E., Pal P. (2018b) Prediction of foaming and surface tension of lean MDEA solutions with corrosion inhibitor (bis(2-hydroxyethyl)cocoalkylamine) in continuous foam fractionation column, Chem. Eng. Comm. 205, 871-880, https://doi.org/10.1080/00986445.2017. 1423063.

Kohl A.L., Nielsen R.B. (1997) Gas Purification, Gulf Professional Publishing, Houston, USA.

Kulkarni A.A., Joshi J.B. (2005) Bubble formation and bubble rise velocity in gas-liquid systems: A Review, Ind. Eng. Chem. Res. 44, 5873-5931.

Mokhatab S., Poe W.A. (2012) Handbook of natural gas transmission and processing, Elsevier, USA.

Olajire A.A. (2017) Corrosion inhibition of offshore oil and gas production facilities using organic compound inhibitors - A review, J. Mol. Liq. 248, 775-808.

Pal P., Banat F. (2016) Comparison of thermal degradation between fresh and industrial aqueous methyldiethanolamine with continuous injection of $\mathrm{H}_{2} \mathrm{~S} / \mathrm{CO}_{2}$ in high pressure reactor, J. Nat. Gas Sci. Eng. 29, 479-487.

Papavinasam S., Doiron A., Panneerselvam T., Revie R.W. (2007) Effect of hydrocarbons on the internal corrosion of oil and gas pipelines, Corrosion 63, 704-712.
Pilon L., Fedorov A.G., Viskanta R. (2002) Analysis of transient thickness of pneumatic foams, Chem. Eng. Sci. 57, 977-990.

Srinivasan S., Veawab A., Aroonwilas A. (2013) Low toxic corrosion inhibitors for amine-based $\mathrm{CO}_{2}$ capture process, Energy Proc. 37, 890-895.

Thitakamol B., Veawab A. (2008) Foaming behavior in $\mathrm{CO}_{2}$ absorption process using aqueous solutions of single and blended alkanolamines, Ind. Eng. Chem. Res. 47, 216-225.

Thitakamol B., Veawab A., Aroonwilas A. (2009) Foaming in amine-based $\mathrm{CO}_{2}$ capture process: experiment, modeling and simulation, Energy Proc. 1, 1381-1386.

Thitakamol B., Veawab A. (2009) Foaming model for $\mathrm{CO}_{2}$ absorption process using aqueous monoethanolamine solutions, Coll. Surf. A: Phy. Eng. Asp. 349, 125-136.

Tse K.L., Martin T., McFarlane C.M., Nienow A.W. (2003) Small bubble formation via a coalescence dependent break-up mechanism, Chem. Eng. Sci. 58, 275-286.

Tse K.L., Martin T.M., McFarlane C.M., Nienow A.W. (1998) Visualisation of bubble coalescence in a coalescence cell a stirred tank and a bubble column, Chem. Eng. Sci. 53, 4031-4036.

Yaro A.S., Khadom A.A., Wael R.K. (2013) Apricot juice as green corrosion inhibitor of mild steel in phosphoric acid, Alex. Eng. J. 52, 129-135. 